\title{
Stress, personal characteristics and burnout among first postgraduate year residents: a nationwide study in Taiwan
}

\author{
BEE-HORNG LUE ${ }^{1,2,3}$, HSIU-JUNG CHEN ${ }^{4}$, CHANG-WEI WANG ${ }^{1}$, YAWEN CHENG ${ }^{5}$ \& MEI-CHING CHEN ${ }^{6}$ \\ ${ }^{1}$ Department of Family Medicine, ${ }^{2}$ Department of Social Medicine, National Taiwan University College of Medicine, Taipei, \\ Taiwan, ${ }^{3}$ Department of Family Medicine, National Taiwan University Hospital, Taipei, Taiwan, ${ }^{4}$ Department of Educational \\ Psychology and Counseling, National Taiwan Normal University, Taipei, Taiwan, ${ }^{5}$ Institute of Health Policy and Management, \\ National Taiwan University College of Public Health, Taipei, Taiwan, ${ }^{6}$ Department of Clinical Psychology, Fu Jen Catholic \\ University College of Medicine, Taipei County, Taiwan
}

\begin{abstract}
Background: Many studies have recognized that the first postgraduate year (PGY-1) of residency training is the most stressful year. Failing to cope with the stress will have negative impact on their work performance and the quality of patient care.

Aims: To investigate stress and burnout in first postgraduate year (PGY-1) residents and to explore the relationship among stress, personal characteristics and burnout.

Methods: A total of 555 PGY-1 residents completed the job stress questionnaire, a Chinese version of the Copenhagen Burnout Inventory, NEO-Five Factor Inventory, Positive and Negative Affectivity Schedule Scale and Coping Strategies Inventory. Working hours were also collected. The association among stress, burnout, personality, coping strategies and affectivity was examined by Pearson correlation. Hierarchical multiple regression was performed to analyze the contribution of predictors to burnout.

Results: Residents identified their working environment and emotional pressures and demands from patients as their primary sources of stress. They exhibited less neuroticism, more conscientiousness and a propensity for positive affectivity, as well as a tendency to use engagement coping strategies. Burnout was positively correlated with stress, neuroticism, negative affectivity, disengagement coping and weekly work hours. Job stress and work hours explained $24.7 \%$ of variance in burnout; personality and coping strategies explained an additional $10.4 \%$ and $5.4 \%$ of variance, respectively. Besides job stress and work-hours, introversion, conscientiousness, having negative affectivity and using disengagement coping predicted burnout.

Conclusions: Resident's personal characteristics were closely related to stress and burnout. Therefore, in addition to assessing their work-related stress, exploring their personal characteristics should be taken into account for early identification of residents at risk of burnout.
\end{abstract}

\section{Introduction}

Many studies have recognized that the first postgraduate year (PGY-1) of residency training is the most stressful year for physicians under professional training and assuming the responsibility of patient care (Alexander et al. 1985; Butterfield 1988; Firth-Cozens 1987; Hsu \& Marshall 1987). According to study results from the Association of Program Directors in Internal Medicine in the United States, residents' stressors can be categorized as follows: situational stressors (e.g. excessive workload, sleep deprivation), personal stressors (e.g. financial issues, inadequate coping skills), and professional stressors (e.g. responsibility for patient care, career planning) (Levey 2001). Failing to cope with these stresses can hamper the resident's health (Butterfield 1988; Collier et al. 2002; Firth-Cozens 1987; Hainer \& Palesch 1998; Shanafelt et al. 2002; Tyssen et al. 2000, 2001). Several studies focusing on resident burnout also showed its negative impact

\section{Practice points}

- First postgraduate year (PGY-1) residents perceived their working situations, emotional pressures and demands from patients as their primary sources of stress.

- Residents had the strength of medical professional as exhibited less neuroticism, more positive affectivity and tended to use engagement coping strategies.

- However, high levels of burnout were demonstrated. Job stress and long work hours played important roles in burnout. Furthermore, introversion, conscientiousness, having negative affectivity and using disengagement coping also predicted burnout.

- For early identification of residents at risk of burnout, emphasis should be placed on assessing their workrelated stresses and exploring their personal characteristics.

Correspondence: Hsiu-Jung Chen, PH.D., Department of Educational Psychology and Counseling, National Taiwan Normal University. No.162, Sec. 1, Heping E. Rd., Da-an District, Taipei City 10610, Taiwan. Tel: +886-2-23511263 ext.502; fax: +886-2-23118674; email: hsiujung@ntnu.edu.tw 
on work performance and the effectiveness of resident education via their amotivational behavior, which even threaten the quality of patient care (Michels et al. 2003; Shanafelt et al. 2002; Williams et al. 2007).

According to the transactional theory of stress articulated by Lazarus and Folkman (1984), an individual's appraisal and coping mechanisms mediate the interaction of personal and environmental stimuli and then influence the outcomes in terms of physical and psychological disturbances and social outcomes such as feeling burned out. A considerable amount of literature points out that personality is an influential antecedent in stress appraisal (David \& Suls 1999; Headey \& Wearing 1989; Schneider 2004; Vollrath 2000, 2001). For example, persons with a propensity for neuroticism tend to perceive stressful situations as threatening. Researchers also found that personality affects an individual's coping strategy selection (Eaton \& Bradley 2008; McCrae \& Costa 1986; Watson \& Hubbard 1996). For example, extraverted persons tend to use problem-solving coping strategies. In contrast, neuroticism-prone persons tend to use problematic strategies like wishful thinking or withdrawal (Connor-Smith \& Flachsbart 2007). Greater stress and burnout occurring in doctors with the personality traits of neuroticism or negative affectivity was indicated in Deary et al.'s study (1996). McManus et al.'s study (2004) also demonstrated that doctors who are most stressed had higher neuroticism levels, and those that reported the most emotional exhaustion also had higher levels of neuroticism as well as being more introverted. They suggest that personality is the cause of stress and burnout. However, it is obscure whether personality and coping strategies contribute to residents' burnout because of the paucity of studies exploring this aspect (Thomas 2004).

The Taiwan Joint Commission on Hospital Accreditation and Department of Health has reformed the residency training program based on the United States Institute of Medicine recommendation that delaying sub-specialized professional training can enhance physicians' clinical competency in providing patient-centered medical care and promoting care quality (Institute of Medicine 2003). Since 2006, all PGY-1 residents undergo one year of general medicine training. Because community medicine is an essential part of the program, residents who work in the hospital have to practice in the community. This new program challenges the adaptability of residents as their role shifts from student to resident, mounting pressures from overloaded residency professional training and accompanying transitional environments. To develop a better training program and enhance residents' well-being, we conducted the present study with the purposes as follows: 1. to identify the sources of stresses which the PGY1 residents perceived, 2. to understand the levels of stress outcome as feelings of burnout, 3. to explore the influencing factors, including personal characteristics to resident burnout.

\section{Methods}

\section{Participants and study design}

There were 1,221 PGY-1 residents total in the 2006 academic year (starting from July, 2006 to June, 2007) in Taiwan, with
855 (70\%) male residents. Considering the residents may need time to adapt themselves fully to responsible medical practice, the survey was conducted in the last half of the PGY-1 year. The investigation was performed from January to June 2007 while the PGY-1 residents were rotating in the community medicine course, which has a lighter workload because the residents are relieved of night duty. Therefore, all the residents during the survey period were subjects of this study which happened to be about half of the PGY1 residents. The questionnaire, accompanied by a stamped return envelope, was distributed to them by the program assistants. In order to obtain a higher response rate, the program directors gave all the residents detailed explanations and some encouragement. The residents filled out their questionnaires anonymously and mailed them directly to the researchers, thereby preserving confidentiality and minimizing response bias.

\section{Measures}

\section{Job Stress}

The questionnaire was developed based on the Cooper's Job Stress Questionnaire (Sutherland \& Cooper 1992), and Tyssen's modified version (Tyssen et al. 2000) where the items were relevant to our residents' working situation. Six items regarding diagnostic skills which we think might be stressful for PGY-1 residents were also included, such as directing the medical interview, mastering the progress of the patient's present illness etc. In total 31 items perceived as stressful were rated on a 5 -point scale $(1=$ never, $5=$ always $)$. Cronbach's alpha coefficient was 0.92. After factor analysis with principal component and varimax rotation methods, five factors were identified: working situational stress, clinical skills stress, emotional pressure and demands from patients, dealing with family and friends' illness, and personal stress (e.g. financial issues). The variances explained by the above factors were $19.97 \%, 13.18 \%, 8.79 \%, 7.52 \%$ and $6.24 \%$ respectively and the overall explained variance was $55.7 \%$.

\section{Burnout}

Burnout refers to a state of fatigue and emotional exhaustion, as a core dimension conceptually, resulted from job-related stresses (Schaufeli \& Buunk 2003). The well-established Maslach Burnout Inventory (MBI) assessing burnout among human services workers has been used widely (Maslach C et al. 1996). Since the newly developed Copenhagen Burnout Inventory (CBI) by Kristensen et al. (2005) measures the status of burnout in a more straightforward way and possesses good psychometric properties, it seems to be an appropriate measure of burnout in a population of health professionals as compared with MBI (Winwood \& Winefield 2004). We used the Chinese version of Copenhagen Burnout Inventory (C-CBI) which was constructed based on CBI and had good reliability and validity demonstrated from studies in Taiwan (Chang et al. 2007; Yeh et al. 2007).

The C-CBI consists of three subscales measuring three domains of burnout in terms of the degree of physical and psychological exhaustion: (1)personal burnout (five items), 
experienced by the person regardless of occupational status; (2) work-related burnout (five items), perceived by the person as related to work; and (3) client-related burnout (six items), perceived by the person as related to work with clients (Yeh et al. 2007). All items have five response categories ranging either from "to a very low degree" to "to a very high degree" or from "never" to "always". Each scale ranges from 0 to 100 points. Typical items are "How often do you feel tired?"; "After a day of work, do you feel exhausted?";"Do you find it hard to work with clients (patients)?"

Cronbach's alpha coefficients in our study were 0.92 for personal burnout, 0.89 for work-related burnout, and 0.86 for client-related burnout.

\section{Personality}

NEO-Five Factor Inventory (NEO-FFI) developed by Costa and McCrae (1992) was applied to measure the personality traits. NEO-FFI comprises five subscales measuring the following aspects of personality: neuroticism, extraversion, openness to experience, agreeableness and conscientiousness. Each subscale contains 12 items and is rated on a 5-point scale. Cronbach's alpha coefficients in our study were 0.87 for neuroticism, 0.82 for extraversion, 0.54 for openness, 0.74 for agreeableness and 0.82 for conscientiousness.

\section{Affectivity}

We used the Positive and Negative Affect Schedule Scale (PANAS scales), developed by Watson et al. (1988), to assess residents' positive and negative affect, covering a broad range of mood status, in the past one week. Each affectivity was measured by ten items which were rated on a 6-point scale. Cronbach's alphas were 0.83 for positive affectivity and 0.90 for negative affectivity in the present study. The PANAS scales have good reliability and validity in mood assessment and exhibit trait-like stability.

\section{Coping Strategy}

We measured coping strategy using the respective sales from Coping Strategies Inventory constructed by Tobin et al. (1984, 1989). Coping Strategy Inventory consists of two scales measuring engagement and disengagement coping strategies. Both scales were further divided into dimensions of emotionfocused and problem-focused subscales. Totally 48 items rating on a 5-point scale were applied. Cronbach's alphas in our study were 0.87 for problem-focused engagement, 0.80 for emotion-focused engagement, 0.80 for problem-focused disengagement and 0.84 for emotion-focused disengagement.

\section{Covariates}

Working hours and residents' well-being has drawn much attention in medical society in recent years (Geurts et al. 1999; Goitein et al. 2005; Gopal et al. 2005). Therefore, we assessed work hours besides age, sex and asked the residents about their perceived social support for work from family, team 402 members, teachers, senior fellows and friends globally as rating on a 5-point scale.

\section{Statistical analysis}

We used descriptive statistics for the research variables and Student's t-test for comparisons between continuous variables. We explored Pearson product-moment correlation to see the association among scales.

Hierarchical multiple regression analysis was carried out to evaluate the contributing factors to outcome measure (burnout). The predictor variables were forcedly entered into the regression analysis in order, based on researchers' presumption in terms of the importance of variable. Because of a paucity of studies and a demonstrated inconsistent association between gender and burnout (Thomas 2004), gender was included as a control variable in block 1 . While job stress and weekly work-hour were significant factors influencing burnout, they were entered in block 2. The distal factor (personality) and proximal factors (affectivity, coping strategy and social support) were entered in block 3 and 4 respectively to examine their influence on burnout after controlling the gender, the job stress and work-hour.

$P$ values $<0.05$ were considered significant with above analysis. All statistical analysis was performed using SPSS for Windows, version 15.0.

\section{Results}

Of the 617 residents surveyed, 555 (90.0\%) have returned completed research materials. $67.7 \%$ was male and $32.3 \%$ was female. The average age of the respondents was $29.35 \pm 2.58$. The gender distribution was not different from that of PGY-1 residents. The weekly work-day was $5.56 \pm 0.54$ day and average work hour per day was $10.03 \pm 2.48$ hours. The weekly work-hour was $56.48 \pm 17.96$ hours. The mean scores of research variables were shown in Table 1.

\section{Job Stress}

Overall, the mean score of five dimensions of stresses perceived by PGY-1 residents was $3.21 \pm 0.48$. The mean score of different dimension was ranking as follows: working situational stress $(3.63 \pm 0.64)$, emotional pressure and demands from patients $(3.27 \pm 0.60)$, personal stress $(3.21 \pm 048)$, clinical skill stress $(2.88 \pm 0.65)$ and dealing with family and friend's illness $(2.81 \pm 0.76)$. There was no statistical difference in stress levels between male and female residents, but male residents perceived higher levels of personal stress $(2.71 \pm 0.60$ vs. $2.57 \pm 0.63, p=0.011)$.

The highest five working situational stresses cited by residents in descending order of scores were sleep deprivation (387, 69.7\%), keeping alert while on call $(374,67.4 \%)$, excessive paperwork and administration responsibility (352, 63.4\%), interruption of work by hassles $(344,62.0 \%)$, and heavy workload (342, 61.6\%). Fear of making mistakes (306, 55.1\%) and fear of litigation $(305,55.0 \%)$ were main stresses among emotional pressure and demands from patients. 
Table 1. Means and standard deviations of research variables among 555 PGY-1 residents in Taiwan, 2007.

\begin{tabular}{|c|c|c|}
\hline & Range & Mean \pm SD \\
\hline \multicolumn{3}{|l|}{ Job stress } \\
\hline Working situational stress & $1-5$ & $3.63 \pm 0.64$ \\
\hline Emotional pressure/ demands from patients & $1-5$ & $3.27 \pm 0.60$ \\
\hline Clinical skill stress & $1-5$ & $2.88 \pm 0.65$ \\
\hline Dealing with family and friends' illness & $1-5$ & $2.81 \pm 0.76$ \\
\hline Personal stress & $1-5$ & $2.67 \pm 0.62$ \\
\hline Total & $1-5$ & $3.21 \pm 0.48$ \\
\hline \multicolumn{3}{|l|}{ Burnout } \\
\hline Personal burnout & $0-100$ & $46.47 \pm 20.02$ \\
\hline Work-related burnout & $0-100$ & $48.87 \pm 18.53$ \\
\hline Patient-related burnout & $0-100$ & $37.84 \pm 15.12$ \\
\hline Total & $0-100$ & $43.99 \pm 15.04$ \\
\hline \multicolumn{3}{|l|}{ Personality } \\
\hline Neuroticism & $12-60$ & $32.59 \pm 6.50$ \\
\hline Extraversion & $12-60$ & $38.02 \pm 5.90$ \\
\hline Openness to Experience & $12-60$ & $37.32 \pm 4.37$ \\
\hline Agreeableness & $12-60$ & $43.53 \pm 4.57$ \\
\hline Conscientiousness & $12-60$ & $40.31 \pm 5.20$ \\
\hline \multicolumn{3}{|l|}{ Affectivity } \\
\hline Positive Affectivity & $0-50$ & $28.94 \pm 5.33$ \\
\hline Negative Affectivity & $0-50$ & $20.55 \pm 7.27$ \\
\hline \multicolumn{3}{|l|}{ Coping Strategy } \\
\hline Emotion-focused Engagement & $0-48$ & $28.49 \pm 5.89$ \\
\hline Problem-focused Engagement & $0-48$ & $26.94 \pm 5.60$ \\
\hline Emotion-focused Disengagement & $0-48$ & $23.51 \pm 6.00$ \\
\hline Problem-focused Disengagement & $0-48$ & $20.22 \pm 6.40$ \\
\hline Social support & $1-5$ & $3.64 \pm 0.74$ \\
\hline
\end{tabular}

\section{Burnout}

The total score of burnout measurement was $43.99 \pm 15.04$. For personal burnout, the mean score was $46.47 \pm 20.02$; for work-related burnout, it was $48.87 \pm 18.53$; for patient-related burnout, it was $37.84 \pm 15.12$. As compared with male residents, the female residents showed higher levels of burnout ( $47.83 \pm 13.38$ vs. $44.95 \pm 14.32, p=0.029)$, especially work-related burnout $(51.39 \pm 16.74$ vs. $47.72 \pm 19.39$, $p=0.027$.

\section{Personality}

Overall, neuroticism (32.59 \pm 6.50$)$ was not so salient among PGY-1 residents. In contrast, more agreeable (43.53 \pm 4.57$)$ and conscientious $(40.31 \pm 5.20)$ types were noted. Female residents had greater openness to experience ( $38.30 \pm 4.38$ vs. $36.87 \pm 4.37, p=0.001)$ and were more extravert $(39.02 \pm 6.11$ vs. $37.58 \pm 5.81, p=0.010)$ as compared with male residents.

\section{Coping strategy}

The mean score for engagement coping strategy was $55.45 \pm 10.39$, which was higher than mean score (43.76 \pm 11.18) for disengagement coping strategy. Male residents demonstrated using disengagement, especially emotionfocused coping strategy more significantly than female residents $(20.69 \pm 6.50$ vs. $19.02 \pm 6.08, p=0.005)$. Female residents tended to use emotion-focused engagement strategy $(28.09 \pm 5.75$ vs. $26.27 \pm 5.55, p=0.001)$.

\section{Affectivity and social support}

Most residents showed a propensity of positive affectivity. There was no significant difference of affectivity between male and female residents. As for social support, residents perceived good support in general and female residents perceived more support than males (3.84 \pm 0.64 vs. $3.54 \pm 0.74, p<0.001)$.

\section{Correlation of burnout with job stress, personality, affectivity, coping strategy and weekly work-hour}

Table 2 demonstrated that all the dimensions of burnout positively correlated with stress, neuroticism, negative affectivity, disengagement coping and weekly work-hour significantly. In contrast, significantly negative correlation was noted between burnout and extraversion, agreeableness and conscientiousness of personality, positive affectivity and engagement coping. We also found that neuroticism and negative affectivity were higher correlated with emotion-focused disengagement coping while conscientious and extravert personality had higher correlation with problem-focused engagement coping. Weekly work-hour was lower correlated with client-related burnout than the other two domains. As noted from the same table, negative affectivity showed positively high correlation with neuroticism $(r=0.634, p<0.001)$ and negatively correlated with other dimensions except openness personality trait. Conversely, positive affectivity negatively correlated with neuroticism but positively correlated with other personality aspects, especially highly associated with extraversion $(r=0.526, p<0.01)$.

\section{Predictors to burnout}

The results of hierarchical multiple regression were shown in Table 3. In model 1 , gender had no predicting power. In model 2, gender, job stress and work-hour accounted for $24.9 \%$ of variance in burnout. Job stress and work-hour had significant predicting power $(\beta=0.358, p<0.001 ; \beta=0.296$, $p<0.001)$ and explained $24.7 \%$ of variance. In model 3 , the predictors explained $34.6 \%$ of variance and personality accounted for $10.4 \%$. Extravert and agreeableness were significant negative predictors $(\beta=-2.46, \quad p<0.001$; $\beta=-0.088, p<0.05)$. The final model demonstrated the set of predictors explained $39.2 \%$ of variance while affectivity, coping strategies and social support accounted for 5.4\% of variance. Among them, negative affectivity and problemfocused disengagement coping significantly predicted burnout $(\beta=0.227, p<0.001 ; \beta=0.188, p<0.001)$. Overall, after controlling factors of gender, job stress and work-hour, the distal factors (more introvert and conscientious) and the proximal factors (propensity of negative affect and problem-forced disengagement coping) indicated increasing tendency of burnout.

\section{Discussion}

The present study found that PGY-1 residents perceived most stressful sources as arising from working situations and emotional pressure and demands from patients. These findings are consistent with those from previous studies (Biaggi et al. 


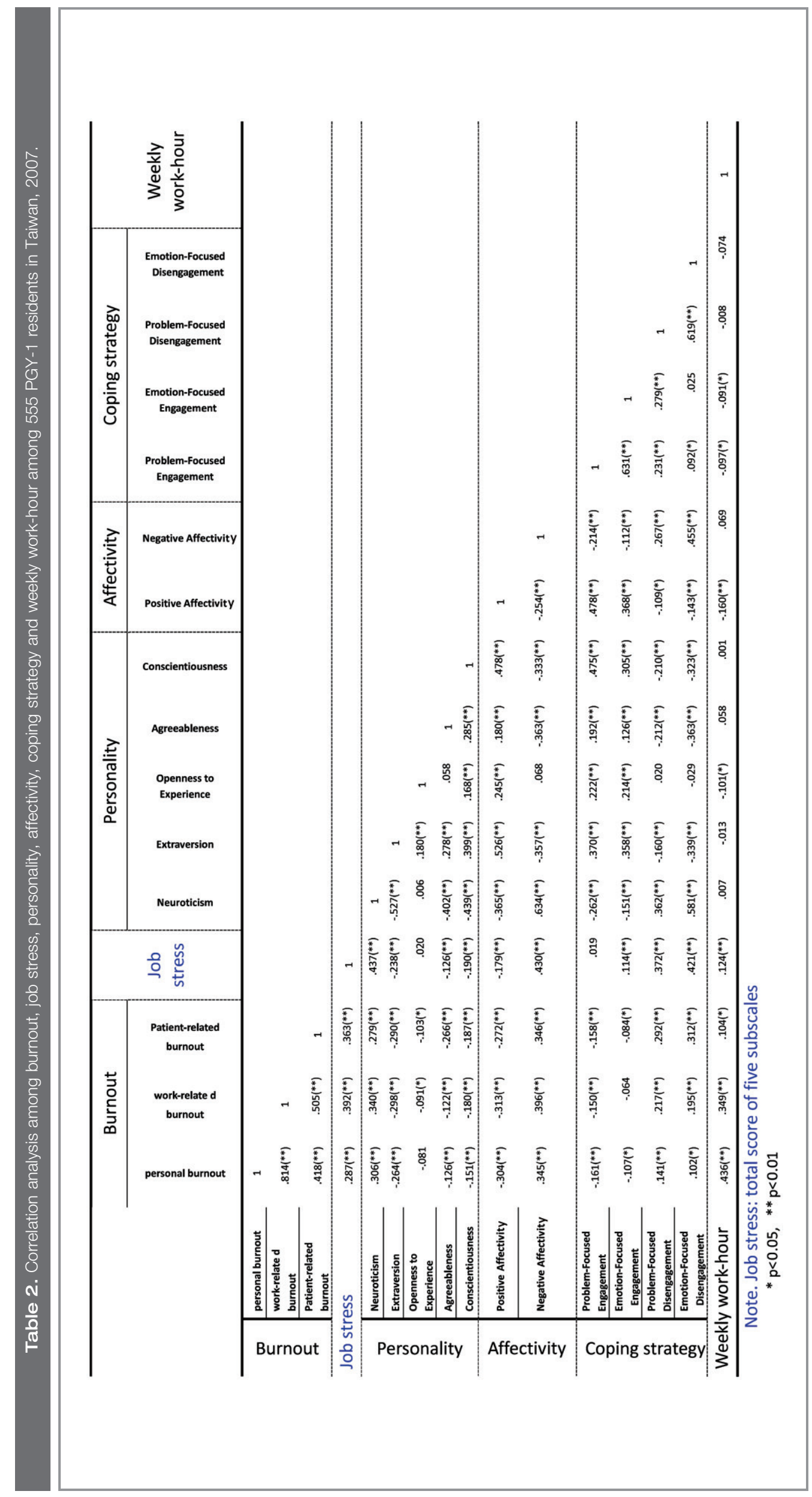




\section{Table 3. Hierarchical regression analysis of predictors to burnout among 555 PGY-1 residents in Taiwan, 2007.}

\begin{tabular}{|c|c|c|c|c|c|}
\hline \multirow{2}{*}{\multicolumn{2}{|c|}{$\begin{array}{l}\text { Dependent variable: burnout } \\
\text { Predict variables }\end{array}$}} & \multicolumn{4}{|c|}{ Standardized coefficients beta and significances } \\
\hline & & \multirow{2}{*}{$\begin{array}{c}\text { Model } 1 \\
0.084\end{array}$} & \multirow{2}{*}{$\begin{array}{c}\text { Model } 2 \\
0.080^{\star}\end{array}$} & \multirow{2}{*}{$\begin{array}{c}\text { Model } 3 \\
0.114^{\star \star}\end{array}$} & \multirow{2}{*}{$\begin{array}{r}\text { Model } 4 \\
0.114^{\star \star}\end{array}$} \\
\hline Block 1 & Gender & & & & \\
\hline Block 2 & $\begin{array}{l}\text { Job stress } \\
\text { Weekly work-hour }\end{array}$ & & $\begin{array}{l}0.358^{\star \star \star} \\
0.296^{\star \star \star}\end{array}$ & $\begin{array}{l}0.206^{\star \star \star} \\
0.305^{\star \star \star}\end{array}$ & $\begin{array}{l}0.212^{\star \star \star} \\
0.268^{\star \star \star}\end{array}$ \\
\hline Block 3 & $\begin{array}{l}\text { Neuroticism } \\
\text { Extraversion } \\
\text { Openness to experience } \\
\text { Agreeableness } \\
\text { Conscientiousness }\end{array}$ & & & $\begin{array}{l}0.068 \\
-0.246^{\star \star \star} \\
-0.062 \\
-0.088^{\star} \\
0.016\end{array}$ & $\begin{array}{l}-0.054 \\
-0.184^{\star \star \star} \\
-0.065 \\
-0.057 \\
0.108^{\star}\end{array}$ \\
\hline Block 4 & $\begin{array}{l}\text { Positive affectivity } \\
\text { Negative affectivity } \\
\text { Problem-focused Engagement } \\
\text { Emotion-focused Engagement } \\
\text { Problem-focused Disengagement } \\
\text { Emotion-focused Disengagement } \\
\text { Social support }\end{array}$ & & & & 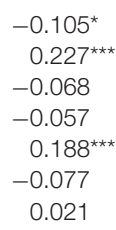 \\
\hline & $\begin{array}{l}\text { Adjusted R square } \\
\mathrm{R} \text { square change } \\
\text { F }\end{array}$ & $\begin{array}{l}0.005 \\
0.007 \\
0.323\end{array}$ & $\begin{array}{c}0.249 \\
0.247 \\
51.371^{\star \star \star}\end{array}$ & $\begin{array}{c}0.346 \\
0.104 \\
31.168^{\star \star *}\end{array}$ & $\begin{array}{c}0.392 \\
0.054 \\
20.581^{\text {*ᄎ* }}\end{array}$ \\
\hline
\end{tabular}

Note: Job stress:total score of five subscales.

Burnout:total score of three subscales.

${ }^{\star} p<0.05,{ }^{\star *} p<0.01,{ }^{* \star *} p<0.001$.

2003; Geurts et al. 1999; Golub et al. 2007; Nyssen et al. 2003; Purdy et al. 1987; Shanafelt et al. 2002). Among the working situational stresses, the excessive time demands, heavy workloads and uncertain future career contribute mostly to resident burnout in the previous studies. But in our study, sleep deprivation, on-call alert, and excessive administrative work were perceived as the most stressful.

Many studies have shown residents from various specialties, internationally, experienced moderate burnout. The prevalence of residents who met the criteria of burnout on MBI ranged from $17 \%$ to $76 \%$ (Biaggi et al. 2003; Shanafelt et al. 2002; Thomas 2004). In our study, mean scores of all dimensions measured by C-CBI were greater than those of a representative sample of 17042 paid employees from a national survey conducted in Taiwan in 2007, in which the score was 32.8 for personal burnout, 28.2 for work-related burnout and 30.1 for client- related burnout (sample size was 7900 for this dimension) (Hsu \& Lee 2008). As compared to the results of Kristensen et al.'s PUMA study (project on Burnout, Motivation, and Job Satisfaction) performed among 1914 persons working in human service professions (Kristensen et al. 2005), our residents' burnout scores were also greater than those of their hospital doctors (i.e. personal burnout 36.6; work-related burnout 39.8; client-related burnout 26.7). Winwood and Winefield (2004) conducted the survey using the same measures for general dental practitioners and also showed lesser degree of burnout with the mean scores for personal, work-related and patient-related burnout being 40.9; 36.6; 33.3 respectively.

According to the PUMA study which defined high degree of burnout as 50 points or more, our study showed $44.7 \%$ of PGY-1 residents had personal burnout, 51.6\% had work-related burnout and $22.7 \%$ had patient-related burnout. These proportion were much greater than those in the results from PUMA study (i.e. $22.2 \%, 19.8 \%$, and $15.9 \%$ for personal, work-related and client-related burnout respectively) (Borritz \& Kristensen 2004). To our knowledge, no study using CBI to assess resident burnout has been conducted yet, thus there is no reference point for comparison. However, our finding indicated PGY-1 residents had high levels of burnout.

The correlation of burnout with stress, personality, affectivity, coping strategies and work-hour was compatible with the previous studies (Deary et al. 1996; McManus et al. 2004). The association between personality and coping strategy, i.e. neuroticism and negative affectivity relating to emotionfocused disengagement while conscientiousness and extraversion relating to problem-focused engagement, was also consistent with the previous findings and suggested that personality affect coping strategy selection (Deary et al. 1996; Eaton \& Bradley 2008).

Stress stems more from the doctor's personality than that from characteristics of the job itself. Higher neuroticism and lower conscientiousness of doctors predictably caused greater stress, burnout feeling and less satisfaction with their medical practice (McManus et al. 2004). The current study indicated that PGY-1 residents exhibited less neuroticism and more positive affectivity, and tended to use engagement coping strategies. These are the strength of medical professionals in which a high level of dedication is required.

However, factors affecting residents prone to burnout need multi-dimensional evaluation in order to reduce the devastating consequences of burnout, such as mental health problems or inadequate patient care. Hierarchical regression was performed and the result demonstrated that job stress and 
work-hour play important roles in resident burnout. Being more extraverted and less conscientious would have favorable outcome. But having negative affect and coping with problemfocused disengagement increases development of burnout. Similarly Deary et al. (1996) showed that job stress levels predicted the degree of burnout experienced by doctors and higher workload related to higher levels of stress.

Regarding the influence of personality, extraverts tend to appraise stressful events as challenges (David \& Suls 1999), respond better to efforts to elevate their mood (Larsen \& Ketelaar 1991) and are better in handling time pressure (Rawlings \& Carnie 1989). Conscientious individuals are hardworking, ambitious and energetic. They persevere in the face of difficulty and tend to be careful and thorough (Liebert \& Spiegler 1998; McManus et al. 2004). Therefore, precautionary care should be taken to avoid residents' excessive or unrealistic self-expectations, so as to prevent burnout.

As to the role of negative emotion, individuals high in negative affectivity express distress, discomfort and dissatisfaction across a wide range of situations (Watson \& Clark 1984) and become more depressed (Deary et al. 1996; Watson \& Clark 1984). They prefer avoidant coping behaviors and use emotion-focused coping rather than problem-focused coping strategies (Cosway et al. 2000; Deary et al. 1996; Eaton \& Bradley 2008). In contrast, people who have relatively high levels of positive affect experience less negative emotion when under stress and have better health (Ong et al. 2006). The current results implied that lasting negative emotion will be detrimental to the adaptation of residents to their work and using more problem-focused disengagement strategies to deal with the stress will predispose them to a decline in energy and thereby lead to burnout.

As expected, the PGY-1 residents facing the intensive and diverse training courses were inevitably prone to experience burnout. The key issues are how to identify the residents at risk early, and to employ effective prevention or intervention strategies.

Although several different residents' assistance programs to combat the burnout or enhance their wellness have been undertaken in the United States (Dabrow et al. 2006; Levey 2001; Pitt et al. 2004; Shapiro et al. 2000), rigorous and prospective studies exploring their effectiveness are needed (Thomas 2004). In Taiwan, to our knowledge, only a Balint group is held in the Department of Family Medicine of few hospitals to support residents and deal with their difficulties. At present, mentoring systems are the only way to supervise PGY-1 residents. The most important finding of this study is that, besides the role of stress, the contribution of personality, negative affectivity and unfavorable coping strategy to burnout should be paid attention to. Thorough understanding of these personal characteristics needs active and intensive monitoring. Therefore, we think, in addition to organizational efforts to reduce work stress, reinforcing the function of mentoring might be the way to help achieve the goal.

To our knowledge, the current study is the first nationwide survey investigating residents' burnout and exploring their personal characteristics in Taiwan. The large, representative sample size and high response rate also strengthen the power of this study. The limitation of this study is that the duration of 406 data collection lasted for 6 months, which might affect the perceived stress and burnout measurement because of the increasing adaptive competency. However, the personality, affectivity and coping strategies are thought to be stable personal characteristics.

In conclusion, the present study revealed high levels of burnout among PGY-1 residents and that their stresses were mainly from working situation, emotional pressure and demands from patients. Personality and coping strategy, in addition to stresses, predicted burnout. For enhancing residents' well-being, personal characteristics, besides work stress, should also be explored in order to identify residents at risk of burnout early, and to provide timely management.

\section{Acknowledgements}

Grants by the National Science Council of Taiwan in funding this research (NSC-95-2516-S-002-01) are gratefully acknowledged. The authors thank all the PGY-1 program directors for their support on this project and all the PGY-1 residents for their participation.

Declaration of interest: The authors report no conflicts of interest. The authors alone are responsible for the content and writing of the paper.

\section{Notes on Contributors}

Dr BEE-HORNG LUE, Dr HSIU-JUNG CHEN and Mr CHANG-WEI WANG conceived the original conception and the design of the study, carried out data collection, analysis and interpretation, and the write-up of the paper. Dr YAWEN CHENG and Dr MEI-CHING CHEN provided the research measures, analyzed, and interpreted the findings, and gave critical comment on the paper.

All authors approved the final manuscript for publication.

\section{References}

Alexander D, Monk JS, Jonas AP. 1985. Occupational stress, personal strain, and coping among residents and faculty members. J Med Educ 60(11):830-839.

Biaggi P, Peter S, Ulich E. 2003. Stressors, emotional exhaustion and aversion to patients in residents and chief residents - what can be done? Swiss Medical Weekly 133(23-24):339-346.

Borritz M, Kristensen TS. 2004. Copenhagen burnout inventory: Normative data from a representative Danish population on personal burnout and results from the puma study on personal burnout, work burnout, and client burnout. Retrieved August 30, 2008, from http:// www.arbejdsmiljoforskning.dk/

Butterfield PS. 1988. The stress of residency. A review of the literature. Arch Med 148(6):1428-1435.

Chang Y-J, Yeh W-Y, Chen C-W, Chen C-J, Shih T-S, Cheng Y. 2007. Distribution and correlates of burnout among paid employees in Taiwan. Taiwan J Public Health 26(1):75-87, [in Chinese].

Collier VU, McCue JD, Markus A, Smith L. 2002. Stress in medical residency: Status quo after a decade of reform? Ann Intl Med 136(5):384-390.

Connor-Smith JK, Flachsbart C. 2007. Relations between personality and coping: A meta-analysis. J Personality Soc Psychol 93(6):1080-1107.

Costa PT, McCrae RR. 1992. Revised NEO Personality Inventory and NEO Five-Factor Inventory. Odessa, FL: Psychological Assessment Resources.

Cosway R, Endler NS, Sadler AJ, Deary IJ. 2000. The Coping Inventory for Stressful Situations: Factorial structure and associations with personality traits and psychological health. J Appl Biobehav Res 5(2):121-143. 
Dabrow S, Russell S, Ackley K, Anderson E, Fabri PJ. 2006. Combating the stress of residency: One school's approach. Acad Med 81(5):436-439.

David JP, Suls J. 1999. Coping efforts in daily life: Role of Big Five traits and problem appraisals. J Personality 67(2):265-294.

Deary IJ, Blenkin H, Agius RM, Endler NS, Zealley H, Wood R. 1996. Models of job-related stress and personal achievement among consultant doctors. Brit J Psychol 87(Pt 1):3-29.

Eaton RJ, Bradley G. 2008. The role of gender and negative affectivity in stressor appraisal and coping selection. Int $\mathrm{J}$ Stress Manage 15(1):94-115

Firth-Cozens J. 1987. Emotional distress in junior house officers. British Med J Clin Res Edu 295(6597):533-536

Geurts S, Rutte C, Peeters M. 1999. Antecedents and consequences of workhome interference among medical residents. Social Sci Med 48(9):1135-1148.

Goitein L, Shanafelt TD, Wipf JE, Slatore CG, Back AL. 2005. The effects of work-hour limitations on resident well-being, patient care, and education in an internal medicine residency program. Arch Int Med 165(22):2601-2606.

Golub JS, Weiss PS, Ramesh AK, Ossoff RH, Johns 3rd MM. 2007. Burnout in residents of otolaryngology-head and neck surgery: A national inquiry into the health of residency training. Acad Med 82(6):596-601.

Gopal R, Glasheen JJ, Miyoshi TJ, Prochazka AV. 2005. Burnout and internal medicine resident work-hour restrictions. Arch Int Med 165(22):2595-2600.

Hainer BL, Palesch Y. 1998. Symptoms of depression in residents: A South Carolina Family Practice Research Consortium study. Acad Med 73(12):1305-1310.

Headey B, Wearing A. 1989. Personality, life events, and subjective wellbeing: Toward a dynamic equilibrium model. J Personality Soc Psychol 57(4):731-739.

Hsu J-H, Lee Y-S. 2008. Survey of Perceptions of Safety and Health in the Work Environment in 2007 Taiwan. Taipei: Institute of Occupational Safety and Health. [in Chinese].

Hsu K, Marshall V. 1987. Prevalence of depression and distress in a large sample of Canadian residents, interns, and fellows. Am J Psych 144(12):1561-1566.

Institute of Medicine 2003. Health Professions Education: A Bridge to Quality. Washington DC: The National Academies Press.

Kristensen TS, Borritz M, Villadsen E, Christensen KB. 2005. The Copenhagen Burnout Inventory: A new tool for the assessment of burnout. Work \& Stress 19(3):192-207.

Larsen RJ, Ketelaar T. 1991. Personality and susceptibility to positive and negative emotional states. J Personality Soc Psychol 61(1):132-140.

Lazarus RS, Folkman S. 1984. Stress Appraisal and Coping. New York: Springer.

Levey RE. 2001. Sources of stress for residents and recommendations for programs to assist them. Acad Med 76(2):142-150.

Liebert RM, Spiegler MD. 1998. Personality: Strategies and Issues. 8th ed. New York: Brooks/Cole Publishing Co.

Maslach C, Jackson SE, Leiter MP. 1996. Maslach Burnout Inventory Manual. 3rd ed. Palo Alto, CA: Consulting Psychologists Pr.

McCrae RR, Costa PT. 1986. Personality, coping, and coping effectiveness in an adult sample. J Personality 54(2):385-405.

McManus IC, Keeling A, Paice E. 2004. Stress, burnout and doctors attitudes to work are determined by personality and learning style: A twelve year longitudinal study of UK medical graduates. BMC Med 2:29.

Michels PJ, Probst JC, Godenick MT, Palesch Y. 2003. Anxiety and anger among family practice residents: A South Carolina family practice research consortium study. Acad Med 78(1):69-79.

Nyssen AS, Hansez I, Baele P, Lamy M, De Keyser V. 2003. Occupational stress and burnout in anaesthesia. Brit J Anaesth 90(3):333-337.
Ong AD, Bergeman C, Bisconti TL, Wallace KA. 2006. Psychological resilience, positive emotions, and successful adaptation to stress in later life. J Personality Soc Psychol 91(4):730-749.

Pitt E, Rosenthal MM, Gay TL, Lewton E. 2004. Mental health services for residents: More important than ever. Acad Med 79(9):840-844.

Purdy RR, Lemkau JP, Rafferty JP, Rudisill JR. 1987. Resident physicians in family practice: Who's burned out and who knows? Family Med 19(3):203-208

Rawlings D, Carnie D. 1989. The interaction of EPQ extraversion with WAIS subtest performance under timed and untimed conditions. Personality Ind Diff 10(4):453-458.

Schaufeli W, Buunk B. 2003. Burnout: An overview of 25 years of research and theorizing. In: Schabracq $\mathrm{M}$, Winnubst J, Cooper $\mathrm{C}$, editors. Handbook of work and health psychology. West Sussex, UK: Wiley. pp 383-429.

Schneider TR. 2004. The role of neuroticism on psychological and physiological stress responses. J Experi Soc Psychol 40(6):795-804.

Shanafelt TD, Bradley KA, Wipf JE, Back AL. 2002. Burnout and selfreported patient care in an internal medicine residency program. Anna Int Med 136(5):358-367.

Shapiro SL, Shapiro DE, Schwartz GE. 2000. Stress management in medical education: A review of the literature. Acad Med 75(7):748-759.

Sutherland VJ, Cooper CL. 1992. Job stress, satisfaction, and mental health among general practitioners before and after introduction of new contract. BMJ 304(6841):1545-1548.

Thomas NK. 2004. Resident burnout. JAMA 292(23):2880-2889.

Tobin DL, Holroyd KA, Reynolds RV, Wigal JK. 1989. The hierarchical factor structure of the Coping Strategies Inventory. Cognitive Therapy Res 13(4):343-361.

Tobin DL, Holroyd KA, Reynolds RVC. 1984. Users manual for the coping strategies inventory. Athens: $\mathrm{OH}$ : Department of Psychology, Ohio University.

Tyssen R, Vaglum P, Gronvold NT, Ekeberg O. 2000. The impact of job stress and working conditions on mental health problems among junior house officers, A nationwide Norwegian prospective cohort study. Med Edu 34(5):374-384.

Tyssen R, Vaglum P, Gronvold NT, Ekeberg O. 2001. Suicidal ideation among medical students and young physicians: A nationwide and prospective study of prevalence and predictors. J Affective Disorders 64(1):69-79.

Vollrath M. 2000. Personality and hassles among university students: A three-year longitudinal study. Eur J Personality 14(3):199-215.

Vollrath M. 2001. Personality and stress. Scand J Psychol 42(4):335-347.

Watson D, Clark LA. 1984. Negative affectivity: The disposition to experience aversive emotional states. Psychol Bull 96(3):465-490.

Watson D, Clark LA, Tellegen A. 1988. Development and validation of brief measures of positive and negative affect: The PANAS scales. J Personality Soc Psychol 54(6):1063-1070.

Watson D, Hubbard B. 1996. Adaptational style and dispositional structure: Coping in the context of the five-factor model. J Personality 64(4):737-774.

Williams ES, Manwell LB, Konrad TR, Linzer M. 2007. The relationship of organizational culture, stress, satisfaction, and burnout with physicianreported error and suboptimal patient care: Results from the MEMO study. Health Care Manage Rev 32(3):203-212.

Winwood PC, Winefield AH. 2004. Comparing two measures of burnout among dentists in Australia. Int J Stress Manage 11(3):282-289.

Yeh W-Y, Cheng Y, Chen C-J, Hu P-Y, Kristensen TS. 2007. Psychometric properties of the Chinese version of Copenhagen burnout inventory among employees in two companies in Taiwan. Int $\mathrm{J}$ Behav Med 14(3):126-133. 